Телегин А. Н., Сарилов М. Ю.

A. N. Telegin, M. Yu. Sarilov

ПОВЫШЕНИЕ ЭФФЕКТИВНОСТИ МАССООБМЕННЫХ АППАРАТОВ ЗА СЧЁТ

ОБОСНОВАННОГО ВЫБОРА КОНТАКТНЫХ УСТРОЙСТВ НА ПРИМЕРЕ ПРЯМОТОЧНОЙ КЛАПАННО-СИТЧАТОЙ ТАРЕЛКИ

\title{
IMPROVING THE EFFICIENCY OF MASS-EXCHANGE MACHINES BY REASONABLE CHOICE OF CONTACT DEVICES BY THE EXAMPLE OF A DIRECT FLOW VALVE-SITTING PLATE
}

Телегин Андрей Николаевич - магистрант кафедры машин и аппаратов химических производств Комсомольского-на-Амуре государственного университета (Россия, Комсомольск-на-Амуре). E-mail: ship.1994@mail.ru.

Mr. Andrey N. Telegin - master's degree student. Chemical Industry Machinery and Equipment Department, Komsomolsk-on-Amur State University (Russia, Komsomolsk-on-Amur). E-mail: ship.1994@mail.ru.

Сарилов Михаил Юрьевич - доктор технических наук, профессор кафедры машин и аппаратов химических производств Комсомольского-на-Амуре государственного университета (Россия, Комсомольск-на-Амуре). E-mail: mahp@knastu.ru.

Mr. Mikhail Yu.Sarilov - doctor of technical Sciences, Professor of the Department of machines and apparatus of chemical production of Komsomolsk-on-Amur state University (Russia, Komsomolsk-on-Amur). E-mail: mahp@knastu.ru.

Аннотация. В процессе выбора контактного устройства в массообмене обычно используется устройство, которое позволяет повысить выработку определённого продукта. Рассмотрим это на примере получения продуктов нефтегазового комплекса. Во время проектирования колонн тарельчатого типа для проведения массообменных процессов в нефте- и газоперерабатывающей промышленности особое внимание уделяется выбору контактных элементов. Оптимальный подбор конструктивных параметров тарелки и направления движения потоков даёт возможность создать такие гидродинамические условия проведения процесса массообмена, при которых достигается минимальное значение брызговынесения, равномерное распределение жидкости между тарелками, эффективное контактирование сплошной и дисперсной фаз.

Summary. In the process of selecting a contact mass-exchange device the equipment which can increase the production of a certain product is commonly used. The authors consider the case of producing oil and gas products. When designing plate-type columns for mass exchange processes in the oil and gas processing industry the focus is concentared on the selection of the contact elements. Optimum selection of the design parameters of the plates and the direction of flow makes it possible to create such hydrodynamic conditions of the mass exchange process, where the minimum value of splashing, equilibrium distribution of liquid between the plates, effectively contacting of the continuous and dispersed phases are achieved.

Ключевые слова: массообмен, контактные устройства, аппарат, выбор, эффективность.

Key words: mass-exchange, contact machines, a machine, selection, efficiency.

УДК 66.02

\section{Введение}

Развитие массообменных аппаратов по пути увеличения мощностей напрямую связано с разработкой массообменных контактных устройств высокой производительности. Не последнюю роль в этом сыграли клапанные тарелки с перекрёстно-прямоточным движением фаз. Данные тарелки обладают повышенной пропускной способностью по жидкости и газу, достаточно высокой эффективностью массопередачи, обеспечивают широкий диапазон устойчивой и 
эффективной работы. Однако на перекрёстно-прямоточных клапанных тарелках при высоких скоростях газа наступает интенсивный прямоток, вследствие чего уменьшается время пребывания жидкости на тарелке и тем самым снижается эффективность массопередачи.

Основным путём решения данной проблемы является увеличение компенсации прямоточного движения взаимодействующих фаз. В связи с этим представляют интерес комбинированные конструкции прямоточных клапанно-ситчатых (ПКС) тарелок, выгодно сочетающих повышенную производительность прямоточных клапанных и высокую эффективность ситчатых тарелок. Просечки, выполненные в клапане и (или) в полотне тарелки, будут способствовать не только компенсации прямоточного движения и увеличению запаса жидкости на тарелке, но также увеличению диапазона устойчивой работы, зоны саморегулирования клапанов, удельной поверхности контакта фаз.

Целью написания статьи являются обоснования эффективности массопередачи по жидкости для прямоточных клапанно-ситчатых тарелок, проведения расчёта гидравлического сопротивления, минимально и максимально допустимых нагрузок по газу.

\section{Основные задачи работы}

- анализ тенденций в разработке клапанных тарелок с перекрёстно-прямоточным движением фаз, обзор специальной литературы, посвящённой проблемам исследования гидравлического сопротивления сухих и орошаемых тарелок, провала жидкости, межтарельчатого уноса и массопередачи на тарелках;

- исследование гидравлического сопротивления, гидродинамических режимов работы, провала и уноса жидкости, эффективности массопередачи на прямоточной клапанно-ситчатой тарелке новой конструкции;

- сопоставление массообменных и гидродинамических характеристик новой тарелки с характеристиками прямоточной клапанной (ПК) тарелки.

Наиболее чётко и выгодно преимущества устройств с компенсацией прямотока за счёт энергии газового потока реализуются в конструкции прямоточной клапанно-ситчатой тарелки, что и показано на рис. 1.

Полотно тарелки представляет собой стальную пластину размером 650 х 180 х 2 мм. В полотне в шахматном порядке проделаны двенадцать отверстий диаметром 40 мм под клапаны, а также два прямоугольных выреза, которые предназначены для переточных устройств (для приёмного кармана и для перетока жидкости на нижележащую тарелку).

Клапаны тарелки устанавливаются в отверстия полотна. По длине пути жидкости образуются восемь рядов по два и один клапан в смежных рядах. Шаг между клапанами (расстояние между рядами) - 50 мм. Расстояние между клапанами - 80 мм. Доля свободного сечения тарелки $-14,95 \%$.

Особенностью конструкции тарелки является наличие просечек в пластине клапана, оснащённых козырьками. Козырьки отогнуты навстречу потоку газа на угол, позволяющий козырькам при максимальном угле открытия пластины клапана располагаться вертикально. Высота козырьков увеличивается в направлении открытия пластины клапана. Благодаря такой конструкции в отверстия клапанов направляется максимально возможная доля общего потока газа и обеспечивается максимальная компенсация прямотока. Также поток газа, выходящий из отверстий клапана, перекрещивается с газом, выходящим из-под смежного по ходу движения жидкости клапана, обеспечивая при этом развитую поверхность контакта фаз и её интенсивное обновление.

Конструктивные параметры клапана новой тарелки оптимальны и выбраны по критериям надёжности и равномерности работы, минимизации провала жидкости, максимизации компенсации прямоточного движения взаимодействующих фаз. 
Телегин А. Н., Сарилов М. Ю.

ПОВЫШЕНИЕ ЭФФЕКТИВНОСТИ МАССООБМЕННЫХ АППАРАТОВ ЗА СЧЁТ ОБОСНОВАННОГО ВЫБОРА

КОНТАКТНЫХ УСТРОЙСТВ НА ПРИМЕРЕ ПРЯМОТОЧНОЙ КЛАПАННО-СИТЧАТОЙ ТАРЕЛКИ

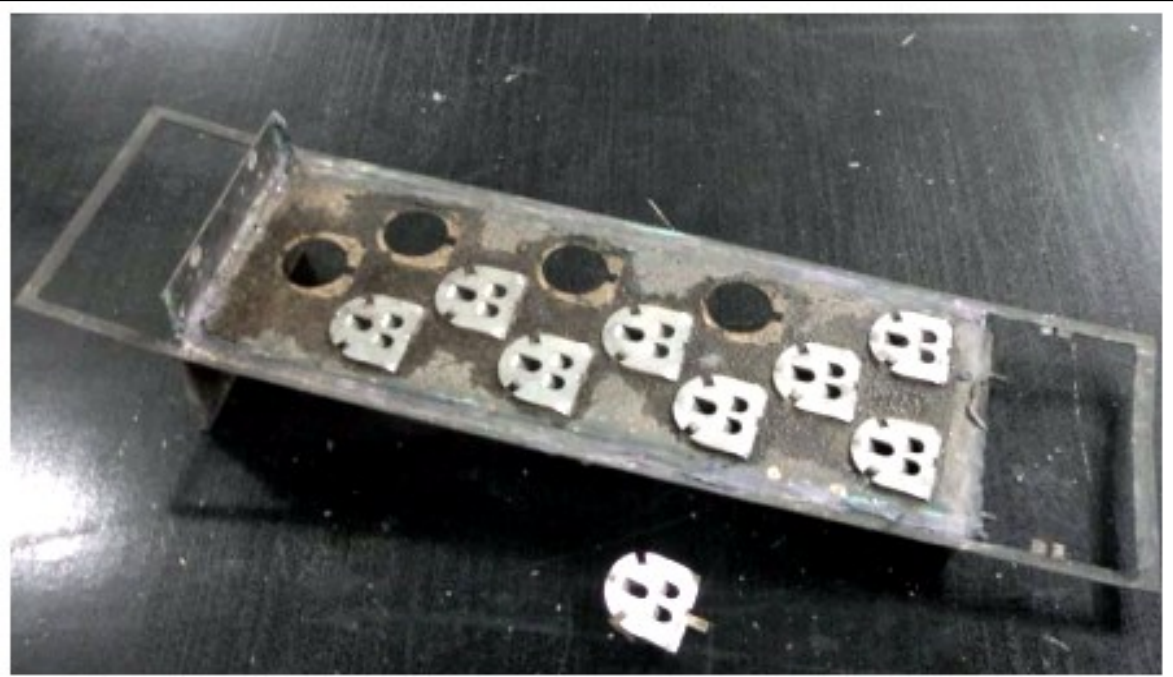

Рис. 1. Прямоточная клапанно-ситчатая тарелка новой конструкции

Для проверки тарелок была собрана экспериментальная установка, схема которой изображена на рис. 2.

Исследование провала жидкости проводилось на системе «вода-воздух».

В ходе эксперимента жидкость, провалившаяся через отверстия тарелки TR1, попадала в специальный отсек, откуда она практически без задержки поступала по трубопроводу диаметром Ду 50 в оттарированную ёмкость Е2 из оргстекла высотой около 1 м и вместимостью более 10 л. Из ёмкости Е2 жидкость удалялась через гидрозатвор при открытом шаровом кране V8. Эксперимент проводился следующим образом. Вначале устанавливался режим работы тарелки, характеризующийся постоянством расходов жидкости и газа. Проваливающаяся жидкость при этом непрерывно выводилась из системы по описанной выше схеме. Далее кран V8 закрывали и замеряли время, необходимое для заполнения жидкостью определённого объёма. По полученным данным определяли величину провала жидкости в $\mathrm{m}^{3} /$ ч. Для каждой опытной точки проводили три измерения, для дальнейшей обработки данных использовалось среднее значение провала.

Эксперименты по определению эффективности массопередачи в жидкости проводили в колонне с одной исследуемой тарелкой ТК1. Первым этапом было заполнение системы водой и насыщение воды углекислым газом. Для этого налаживали циркуляцию воды по схеме «ак $\rightarrow \mathrm{P} 1 \rightarrow \mathrm{A} 1 \rightarrow \mathrm{T} 1 \rightarrow$ бак», затем начинали подавать в поток воды на входе в абсорбционную колонну А1 углекислый газ из баллона. Время насыщения составляло около 15 мин, в результате достигалась концентрация углекислого газа $\sim 8 \ldots 12$ моль/м². Затем начинали подавать жидкость в колонну, при этом углекислый газ небольшим потоком продолжал подаваться в абсорбционную колонну А1 для восстановления своей концентрации в воде. После вывода колонны на заданный режим работы отбирали пробы воды на входе и на выходе с тарелки.

На одной опытной точке проводили два отбора (для обработки бралась средняя величина).

Далее определяли величину $p H$ отобранных проб. По формуле (1) находили концентрацию $\mathrm{C}_{2}$ в пробах $\vartheta_{k}$, а по зависимости (2) определяли эффективность тарелки по Мерфри:

$$
\begin{gathered}
\vartheta_{\kappa}=3,797 \cdot 10^{-3}+\exp [1,959 \cdot(4,09-p H)] ; \\
E_{M L}=\frac{\vartheta_{\kappa}\left(p H_{H}\right)-\vartheta_{\kappa}\left(p H_{H}\right)}{\vartheta_{\kappa}\left(p H_{H}\right)-3,992 \cdot 10^{-3}},
\end{gathered}
$$




\section{Учёные записки \\ Комсомольского-на-Амуре государственного технического университета}

где $E_{M L}$ - общая эффективность массопередачи по жидкости; $\vartheta_{\kappa}\left(p H_{H}\right), \vartheta_{\kappa}\left(p H_{H}\right)-$ концентрации карбонатов и бикарбонатов на входе и на выходе с тарелки соответственно, моль/л; $p H-$ величина $p H$ отобранных проб.

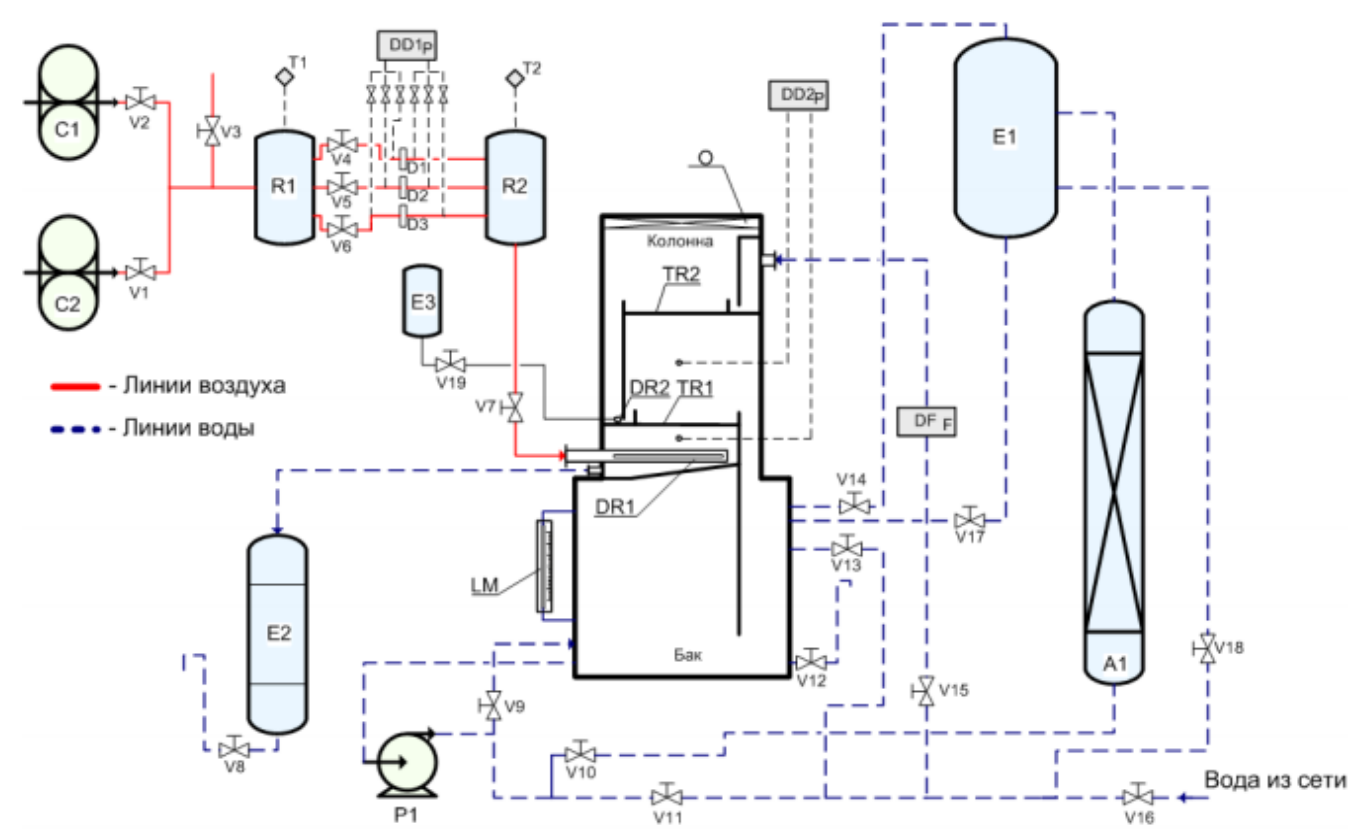

Рис. 2. Схема экспериментальной установки:

C1, C2 - компрессоры; P1 - насос; TR1, TR2 - тарелки; R1, R2 - ресиверы; E1 - бак;

E2 - ёмкость для сбора провала; Е3 -ёмкостьдля трассера; А1 - абсорбционная колонна;

DR1 - распределитель воздуха; DR 2 - распределитель трассера; LM - уровнемер;

$\mathrm{O}$ - отбойник; D1, D2, D3 - диафрагмы; DD $1 p, \mathrm{DD} 2{ }_{p}$ - блоки дифференциальных манометров;

T1, T2 - термометры; $\mathrm{DF}_{F}$ - расходомер; V1-V19 - запорная арматура

Проведёнными экспериментами подтверждено, что зависимость гидравлического сопротивления сухой прямоточной клапанно-ситчатой тарелки от фактора скорости газа в рабочем сечении тарелки имеет три характерные области. При малых скоростях газа клапаны тарелки находятся в нижнем положении и газ проходит через просечки в клапане и начальный зазор между клапаном и полотном тарелки (участок I).

Гидравлическое сопротивление тарелки в этой области пропорционально квадрату скорости газа. При достижении значения фактора скорости газа ФІ-II, при котором сила, действующая на клапан со стороны газа, становится равной его весу, клапан начинает подниматься. Такой режим работы тарелки соответствует режиму саморегулирования (участок II). Визуально было отмечено, что в этом режиме все клапаны на тарелке совершают плавные непрерывные колебательные движения, отличающиеся по фазе и амплитуде. С увеличением нагрузки по газу клапаны приподнимаются выше, увеличивая свободную поверхность для выхода газа. Это происходит до того момента, когда клапаны не поднимутся в крайнее верхнее положение (до $\Phi_{\text {II-II }}$ ). Далее свободное сечение становится постоянным и сопротивление в этой области растёт пропорционально $\Phi_{P}^{2}$ (участок III).

На основе анализа опытных данных на новой тарелке в работе предложено общее уравнение сопротивления сухих прямоточных клапанно-ситчатых тарелок: 
Телегин А. Н., Сарилов М. Ю.

ПОВЫШЕНИЕ ЭФФЕКТИВНОСТИ МАССООБМЕННЫХ АППАРАТОВ ЗА СЧЁТ ОБОСНОВАННОГО ВЫБОРА

КОНТАКТНЫХ УСТРОЙСТВ НА ПРИМЕРЕ ПРЯМОТОЧНОЙ КЛАПАННО-СИТЧАТОЙ ТАРЕЛКИ

$$
\begin{aligned}
& \Delta P_{\mathrm{I}}\left\{\begin{array}{l}
\frac{1}{2 \cdot g} \cdot \xi_{\text {зак }} \cdot \Phi_{P}^{2} \cdot\left(\frac{F_{P}}{F_{\mathrm{O}}}\right)^{2} \quad 0 \leq \Phi_{P}<\Phi_{\mathrm{I}-\mathrm{II}}, \\
\left(\frac{A}{\exp \left(C \cdot \Phi_{P}\right)}+B\right) \cdot \Phi_{P}{ }^{2} \quad \Phi_{\mathrm{I}-\mathrm{II}} \leq \Phi_{P}<\Phi_{\mathrm{II}-\mathrm{III}},
\end{array}\right. \\
& \frac{1}{2 \cdot g} \cdot \xi_{\text {отк }} \cdot \Phi_{P}^{2} \cdot\left(\frac{F_{P}}{F_{\mathrm{O}}}\right)^{2} \quad \Phi_{P} \geq \Phi_{\text {II-III }},
\end{aligned}
$$

где $\Delta P$ - гидравлическое сопротивление сухой тарелки, мм вод. ст.; $\xi_{\text {зак }}-$ коэффициент сопротивления тарелки с закрытыми клапанами, отнесённый к скорости газа в отверстиях полотна тарелки; $\xi_{\text {отк }}$ - коэффициент сопротивления тарелки с полностью открытыми клапанами, отнесённый к скорости газа в отверстиях полотна тарелки; $F_{P}$ - рабочая площадь тарелки, равная площади свободного сечения колонны за вычетом площади одного перелива, ${ }^{2} ; F_{\text {O }}$ - площадь всех отверстий в полотне тарелки, $м^{2} ; \Phi_{P}-$ фактор скорости газа, отнесённый к рабочей площади тарелки $F_{P}$, кг $\Gamma^{0,5} /\left(\mathrm{M}^{0,5} \cdot \mathrm{c}\right): \Phi_{P}=W_{P} \cdot \sqrt{\rho_{\Pi}} ; W_{P}$ - скорость газа в рабочем сечении тарелки $F_{P}$. м/с; $\rho_{\Pi}$

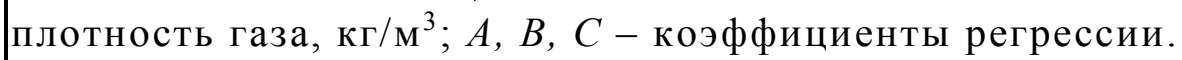

Коэффициенты $A, B, C$ в данном уравнении определяются после статистической обработки экспериментальных данных для конкретной конструкции тарелки.

Схема зависимости гидравлического сопротивления газожидкостного слоя $\Delta P_{2}$ от фактора скорости газа изображена на рис. 3.

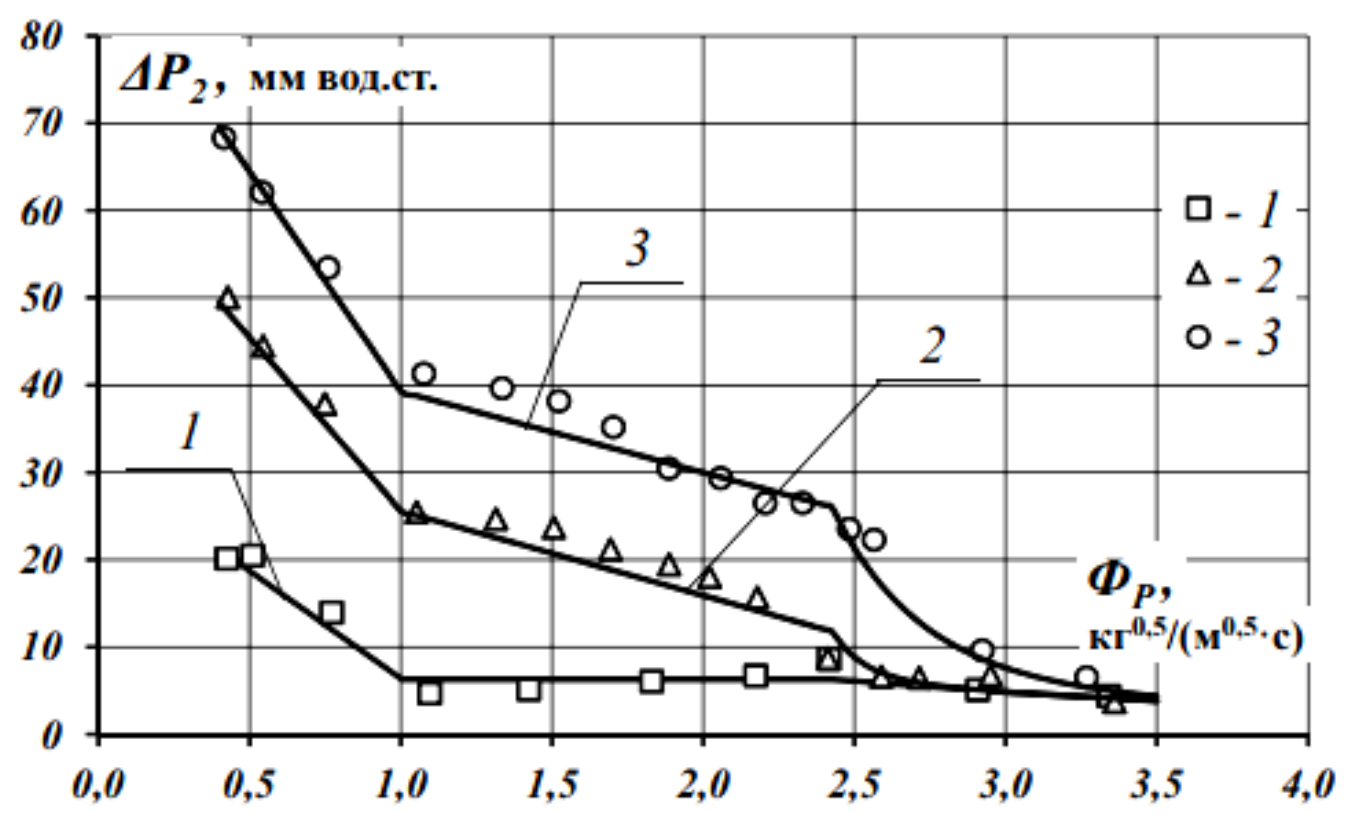

Рис.3. Зависимость гидравлического сопротивления газожидкостного слоя $\Delta P_{2}$ от фактора скорости газа $\Phi_{P} \Phi_{P}\left[L_{V} 29,8 \mathrm{~m}^{3} /(\mathbf{M} \cdot \mathbf{4})\right]$ 


\section{Учёные записки \\ Комсомольского-на-Амуре государственного технического университета}

\section{Выводы}

На основе анализа тенденций в разработке клапанных тарелок с перекрёстно-прямоточным движением фаз выявлено, что конструирование комбинированных прямоточных клапанноситчатых тарелок является перспективным направлением, позволяющим существенно увеличить эффективность массопередачи.

По результатам сопоставления установлено, что прямоточная клапанно-ситчатая тарелка имеет больший диапазон устойчивой работы, чем прямоточная. Особенно эффективна, по мнению автора, замена прямоточных клапанных тарелок на новые прямоточные клапанно-ситчатые в аппаратах с невысокой производительностью по газу. Доказано, что минимальные допустимые значения фактора скорости газа новой тарелки ПКС в 1,5..2,0 раза меньше по отношению к тарелке ПК.

\section{ЛИТЕРАТУРА}

1. Телегин, А. Н. Повышение эффективности массообменных аппаратов за счёт обоснованного выбора контактных устройств / А. Н. Телегин, М. Ю. Сарилов // Учёные записки Комсомольского-на-Амуре государственного технического университета. Науки о природе и технике. - 2017. - № I-1(29). - С. 33-37.

2. Антонов, М. А. Компьютерное моделирование жёсткости несущих элементов контактных устройств массообменного аппарата / М. А. Антонов, Р. 3. Латфуллин, И. А. Сабанаев // Вестник Казанского технологического университета. - 2016. - Т. 19 (№ 23). - С. 82-84.

3. Иванов, И. В. Массообмен в насадочной колонне экстрактивной ректификации / И. В. Иванов, В. А. Лотхов, К. А. Моисеева, Н. Н. Кулов // Теоретические основы химической технологии. - 2016. - Т. 50 (№ 5). - С. 485-495.

4. Кологривов, М. М. Численное моделирование тепло- и массообмена в эжекционном аппарате М. М. Кологривов, В. П. Бузовский // Инженерно-физический журнал. - 2016. - Т. 89 (№ 1) - С. 158-169.

5. Лапшина, С. В. Оценка прочностных характеристик оборудования / С. В. Лапшина, Е. М. Тупикина // Химическая технология. Химические производства: материалы V Международной конференции-школы по химической технологии ХТ'16, Волгоград, 2016. - С. 89-90. 